\title{
An understanding the genetic basis of congenital heart disease
}

\author{
Smitha Ramegowda, Nallur B. Ramachandra \\ Department of Studies in Zoology, Human Genetic Laboratory, University of Mysore, Manasagangothri, Mysore - 570006, India
}

The recent exponential increase in the knowledge of genetics has revolutionized the understanding of congenital heart diseases (CHDs) during the past few decades. Prior studies have reported the influence of Mendelian disorders on CHDs to be very small, when compared to the polygenic inheritance, which constituted a higher percentage. The recent findings of candidate genes responsible for CHDs have provided new insights into the genetic basis of heart malformation. Here we reviewed the understandings of different types of heart lesions associated with syndromes for which genetic etiologies are apparent, as well as the recent developments involving the molecular pathways involved in CHDs in case of human beings. The similar mutations, which are the devastating events of molecular mechanism, may be the cause of different types of CHDs indicating single gene defects as the cause of different apparent phenotypes. An integrated simple model will explain the causes of presently well known CHDs. This review provides updated information on the genetic basis for cardiac defects which helps to understand, identify, prevent and treat individuals who might be at risk at an early stage. There is a need to find heart defects as early as possible so that they can be treated while the heart is still forming.

Key Words: Congenital heart disease, Syndrome, Chromosome, GATA 4, NKX-2.5, Transcription factors

\section{Introduction}

Congenital heart diseases (CHDs) are the most common of all birth defects and are the leading cause of mortality in the first year of life. It has been well established that abnormal heart development is the major cause of the disease, which is mainly due to the com-

bined effect of one or more genes interacting with various environmental risk factors. The development of the heart involves a series of collective molecular and morphogenetic events. Any deviation from the normal course, results in a disastrous form of disease. ${ }^{[1]}$ The complexity inherent in heart development is reflected on the expression of myriads of genes. Candidate genes that play critical functions at specific stages of cardiac development are emerging from studies in vertebrate and invertebrate model organisms, providing possible cause for various forms of CHDs in human beings. ${ }^{[1-2]}$ The recent discovery that dominant inherited transcription factor mutations cause CHDs has brought direct medical relevance to the study of cardiac transcription factors in heart development. ${ }^{[3]}$ This review focuses on the understandings of the different types of CHDs with some of the associated chromosomal syndromes and the recent developments involving the genetics of $\mathrm{CHDs}$ in human beings.

\section{Incidence}

CHDs are the most common single group of congenital abnormalities accounting for about $30 \%$ of the total abnormalities. ${ }^{[4]}$ In most patients, CHDs occur as an isolated malformation, but also about $33 \%$ have associated anomalies. ${ }^{[5]}$ World wide CHDs in children continues to be a major public problem with the incidence in different studies varying from 1-17.5/1000 live births 
[Table 1] and $10 \%$ of spontaneously aborted fetus. ${ }^{[6]}$ The available data on CHDs in India shows an incidence of $1-5 / 1000$ live births..$^{[7-8]}$

\section{Classification of CHDs}

The CHDs could take place in any side of the heart: Atrial, ventricular or vascular. The common defects are classified according to: a) side of the affected heart, b) communication or short circuit between both hearts chambers and c) Presence or absence of cyanosis. ${ }^{[9]}$ Figure 1 presents the schematic diagram of normal heart, which will help to understand different types of CHDs. According to the Merck manual of Diagnosis ${ }^{[10]}$ the first eight $\mathrm{CHDs}$ are the common lesions, which account for $85 \%$ of all cases and the remaining (15\%) account for variety of rare and complex CHDs.

(1) Atrial Septal Defect (ASD): A septal defect is a hole in different part of the atrial septum which lets some amount of blood from the left atrium to right atrium instead of flowing into left ventricle. It may be single or multiple and can be located anywhere in the atrial septum. Based on this, the ASDs are classified into 3 major types depending on the different part of the septum: a) Ostium secundum (Fossa ovalis), b) Ostium primum and c) Sinus venosum defect.

Table 1: Frequency of congenital heart diseases in different parts of the world based on the available literature

\begin{tabular}{lccl}
\hline Country/City & Year & $\begin{array}{c}\text { Frequency/ } \\
\mathbf{1 0 0 0}\end{array}$ & \multicolumn{1}{c}{ References } \\
\hline England & $1957-1971$ & $6-9$ & Bound et al, ${ }^{[53]}$ \\
Liverpool & $1960-1969$ & 6.6 & Kenna et al, ${ }^{[5]}$ \\
Prague & $1977-1984$ & 6.64 & Samanek et al, ${ }^{[55]}$ \\
Lebanon & $1980-1995$ & 11.5 & Bitar et al, ${ }^{[56]}$ \\
Bohemia & $1980-1990$ & 6.61 & Samanek et al, ${ }^{[57]}$ \\
Western Australia & $1980-1989$ & 7.65 & Bower and Ramsay ${ }^{[58]}$ \\
NSW and & & & \\
ACT2-Australia & $1981-1984$ & 4.3 & Kidd et al[59] \\
Qatar & $1984-1994$ & 12.23 & Robida et al, ${ }^{[60]}$ \\
Norway & $1987-1990$ & 10.2 & Meberg et al, ${ }^{[61]}$ \\
Karachi & $1987-1992$ & 4 & Hassan et al, ${ }^{[62]}$ \\
Central Australia & $1993-2000$ & 17.5 & Bolisetty et al, ${ }^{63}$ \\
South Australia & $1993-2000$ & 12 & Annual report 2000 ${ }^{[64]}$ \\
Oman & $1994-1996$ & 7.1 & Subramanyan et al, ${ }^{[65]}$ \\
Bosnia & $1994-1999$ & 6.12 & Begic et al, ${ }^{[66]}$ \\
Egypt & $1995-1996$ & 1.01 & Bassili et al, ${ }^{[67]}$ \\
Shimla & 1995 & 2.25 & Thakur et al, ${ }^{[8]}$ \\
Saudi Arabia & $1997-2000$ & 2.4 & Alabdulgader ${ }^{[68]}$ \\
New Delhi & 2001 & 4.2 & Chadha et al, ${ }^{[7]}$ \\
\hline
\end{tabular}

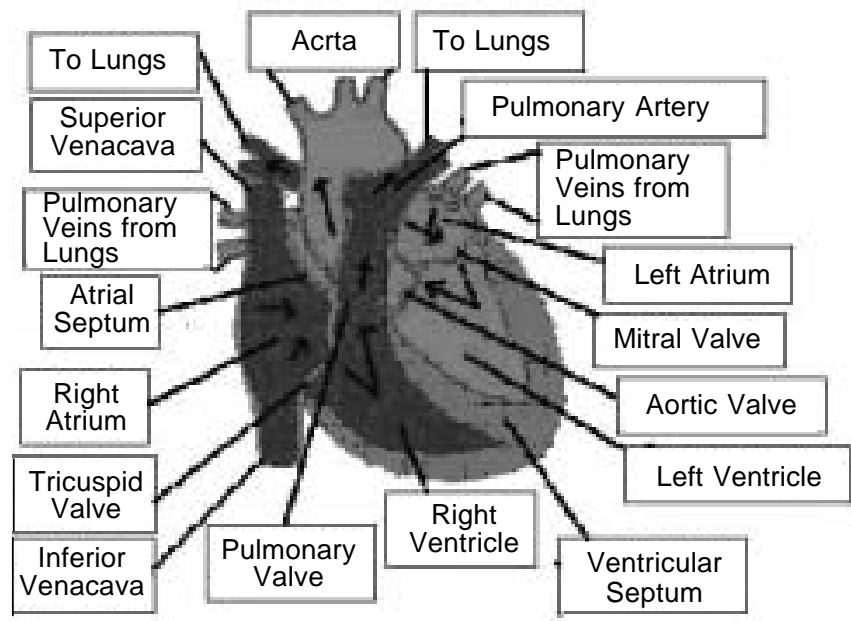

Figure 1: Schematic diagram of normal heart

(2) Ventricular Septal Defect (VSD): A septal defect is a hole, existing between the lower chambers of the heart. Oxygen rich blood from the lungs is pumped into the aorta from the left ventricle. During this process with VSD some amount of blood is passed into the right ventricle and into the pulmonary artery back to the lungs. As the heart has to pump extra blood and is overworked it might transform the septum into a honey combed Swiss cheese structure with sieve like fenestrations. It is classified into 2 main types according to their location relative to the components of the septum. The common types are perimembranous and trabecular.

(3) Patent Ductus Arteriosus (PDA): Ductus arteriosus, the temporary duct connecting the left pulmonary artery to the aorta in the fetal heart, fails to close after birth. This allows blood to mix between the pulmonary artery and the aorta, which results in too much blood traveling to the lungs.

(4) Pulmonary Stenosis (PS): Narrowing of the pulmonary valve between right ventricle and the pulmonary artery is called pulmonary stenosis. This results in the right ventricle pumping harder than normal to overcome the obstruction.

(5) Aortic Stenosis (AS): Narrowing of the aortic valve between the left ventricle and the aorta is called aortic stenosis. Normally there are 3 leaflets or cups in a valve, but in a stenotic valve there is one (unicuspid) or two (bicuspid). Obstruction may be valvular, subvalvular (sub aortic) or supra valvular. This makes it hard for the heart to pump blood to the body.

(6) Coarctation of the aorta (COA): It is a constricted 
segment of the aorta that obstructs blood flow to the lower part of the body and increases blood pressure above the constriction. It usually occurs as isolated disease, but may occur with a VSD, sub aortic stenosis or complex CHDs.

(7) Tetralogy of Fallot (TOF): TOF is made up of 4 separate components: a) VSD, that lets blood pass from the right to the left ventricle without going through the lungs and b) a narrowing (stenosis) at or just beneath the pulmonary valve. This narrowing partially blocks the blood flow from the right side of the heart to the lungs.

c) The right ventricle is more muscular than normal, and d) the aorta lies directly over the VSD. Collectively, this results in cyanosis or blue baby, which may appear soon after birth, in infancy or later in childhood.

(8) Transposition of the great arteries (TOA): The great arteries are pulmonary artery and the aorta. The normal positions of the arteries are reversed in this type of defect. The aorta is connected to the right ventricle, while the pulmonary artery is connected to the left ventricle. This results in the right ventricle pumping oxygen poor blood to different parts of the body and the left ventricle pumping oxygen rich blood to the lungs. This defect is commonly associated with VSD, PS, heart block and an Ebstein like malformation of the tricuspid valve, which helps in communicating the oxygen rich blood to different parts of the body.

(9) Atrioventricular Septal Defect (AVSD): A large hole in the centre of the heart exists where the wall between the upper chambers joins the wall between the lower chambers. This is called as a complete AVSD. In case of partial AVSD, either the upper or the lower part of the septum is affected. In addition, the tricuspid and mitral valves that normally separate the hearts upper and lower chambers are not formed as individual valves; instead, a single large valve is formed. This large opening in the centre of the heart lets blood to flow in all direction inside the heart.

(10) Persistent truncus arteriosus: It is a complex malformation where only one artery arises from the heart and forms the aorta and pulmonary artery. That means the pulmonary arteries then branch off this common artery. This defect is found in association with VSD.

(11) Tricuspid Artesia (TA): The valve between the right atrium and the right ventricle is missing. As a re- sult, oxygen-poor blood is pumped into the body along with the oxygen-rich blood. This results in cyanosis or blue baby. This defect is found in association with ASD, VSD and PDA.

(12) Pulmonary Artesia (PA): In this case no pulmonary valve exists; therefore blood cannot flow from the right ventricle into the pulmonary artery and on to the lungs. The only way for the blood to reach the lungs is the ductus arteriosus which is found during the fetal condition which closes after birth. The mixing of oxygen rich blood and oxygen poor blood results in cyanosis.

(13) Total anomalous pulmonary venous connection (TAPVC): In this case, all the pulmonary veins drain into the right atrium instead of left atrium, which brings the mixing of the blood. In addition to this, there is also presence of ASD and VSD, which results in cyanosis. There are three main types of TAPVC, depending on where the pulmonary veins drain. They are referred to as supracardiac, intracardiac, and infracardiac.

(14) Hypoplastic left heart syndrome (HLHS): In this condition the left ventricle and the aorta are small and underdeveloped. Therefore, the mitral and aortic valves are usually tiny or absent. It is one of the top three heart abnormalities to cause problems in the newborn.

(15) Double outlet right ventricle (DORV): It is a most uncommon defect in which both the pulmonary artery and aorta arises from the right ventricle, each with its own outflow tract and valve.

(16) Single ventricle / univentricular heart: It refers to a congenital malformation in which two atria are related to one ventricle that qualifies as left, right or indeterminate ventricle on purely morphologic ground.

(17) Ebstein's anomaly (EA): In this case there is a downward displacement of the tricuspid valve into the right ventricle. It is usually associated with an ASD.

(18) Dextrocardia (heart on the right): If the developing heart tube bends to the left instead of the right, then the heart is displaced to the right and develops in a mirror image of its normal state. This is a condition called situs inversus. In many a cases Dextrocardia heart functions normally unless there are no associated vascular abnormalities. In cases where the heart is the only organ, which is transposed, known as isolated Dextro- 
cardia, there are usually other severe cardiac abnormalities associated with it.

Table 2 provides incidence of various types of CHDs in the world population, which indicates that VSD, ASD and PDA are more prevalent both at National and International level.

Despite a large number of cardiac diseases that exist, there are only a limited number of physiological disturbances that can be produced. It is usually present in infancy as i) Symptomatically with cyanosis, congestive heart failure, shock, Arrhythmias, ii) Asymptomatically with heart murmur and iii) Others which includes different respiratory tract infections and growth failure.

The diagnosis of CHDs includes careful physical and cardiovascular examination, chest radiography, electrocardiography, echocardiography, cardiac catheterization, cineangiography and cardiac MRI. ${ }^{[11]}$

\section{Etiology}

Most of the congenital heart defects are sporadic. The major genetic cause for congenital heart defects includes the following: (a) chromosomal disorders and single gene disorders constituting $8 \%$ (b) $2 \%$ of environmental teratogens and (c) $90 \%$ multifactorial disorders. ${ }^{[12]} \mathrm{A}$

Table 2: The frequency of different types of congenital heart disease (CHDs) at international and national leve| ${ }^{[54,66,57,67,68,65,69-71]}$

\begin{tabular}{lcc}
\hline Type of diseases $^{*}$ & \multicolumn{2}{c}{ CHDs in \% } \\
\cline { 2 - 3 } & International & National \\
\hline VSD & 25.5 & 30.3 \\
ASD & 17.93 & 26.6 \\
PDA & 13.3 & 15.4 \\
TGA & 9.95 & NA \\
PS & 9.2 & 6.9 \\
AVSD & 7.5 & NA \\
TOF & 6.02 & 10.4 \\
COA & 5.8 & 1.8 \\
AS & 4.8 & 4.1 \\
HLHS & NA & 1.5 \\
EA & NA & 1.5 \\
TA & NA & 1.5 \\
CCHD WITH DEXTROCARDIA & NA & 1.5 \\
Others & NA & 10.6 \\
\hline VSD V V
\end{tabular}

VSD- Ventricular Septal Defect, ASD- Atrial Septal Defect, PDA - Patent Ductus Arteriosus, TGA - Transposition of Great Arteries, PS-Pulmonary Stenosis, AVSD- Atrioventricular Septal Defect, TOF- Teratology Of Fallot, COA Coarctation Of Aorta, AS- Aortic Stenosis, HLHS- Hypoplastic Left Heart Syndrome, EA - Ebstein Anomaly, TA -Tricuspid Artesia, CCHD-Cyanotic Congenital Heart Defects, Others- includes other rare defects, NA- not available. multifactorial means both genetic and environmental factors interact, to interfere with the development of the heart. Increased incidence of CHDs has been noted with intrauterine viral infections, maternal drug and alcohol consumption during first trimester of pregnancy and pregnancy-induced systemic maternal disease. ${ }^{[13]} \mathrm{Al}-$ though most CHDs occur as a sporadic event, many diseases are part of a well-defined genetic basis. ${ }^{[12,14]}$ In addition to Mendelian disorders, certain types of CHDs are associated to single gene or single locus defects.

\section{Chromosomal anomalies}

The association of CHDs with chromosomal anomalies varies between $4-12 \% .{ }^{[15]}$ The following are some of them:

(a) Trisomy 21 (Down syndrome): This chromosomal defect has the highest association with major heart abnormalities. At least $40 \%$ of Trisomy 21 children will have heart disease; furthermore, $50 \%$ of those children with heart abnormalities will specifically be affected with AVSD. ${ }^{[16]}$

(b) Trisomy 18 (Edwards Syndrome): This is the second most common autosomal aneuploidy after Down syndrome. Common CHDs include VSD, AVSD, double outlet right ventricle, and hypoplastic left heart. ${ }^{[17]}$

(c) Trisomy 13 (Patau Syndrome): Many die in the neonatal period with this syndrome. Common CHDs include ASD, VSD, PDA and cardiac malpositions especially Dextrocardia (6\%). ${ }^{[18]}$

(d) $45 \mathrm{X}$ (Turner Syndrome): About 10\% of girls with this syndrome have a clinically evident heart defect and a further $10 \%$ will display cardiac disease on echocardiography. ${ }^{[19]}$ Common CHDs include VSD, COA, bicuspid aortic valve, hypoplastic left heart, mitral valve prolapse, and idiopathic aortic root dilatation. ${ }^{[20]}$

(e) Tetrasomy 22q (cat eye syndrome): The important features of this syndrome are iris colobomata, ear tags and imperforate anus. The CHDs association is found to be $30 \%$ of the patients with total anomalous pulmonary venous drainage as major problem. ${ }^{[21]}$

(f) Tetrasomy 12q (pallister killian syndrome): This is associated with mosaicism of chromosome. The CHDs association is found to be $25 \%$ of the patients that in- 
cludes VSD, COA, PDA, ASD, and AS. ${ }^{[22]}$

(g) Fragile -X Syndrome: It is caused by a trinucleotide repeat expansion (CGG) in the fragile $X$ mental retardation gene (FMR1) at Xq27.3. ${ }^{[23]}$ Cardiac disease include mitral valve prolapse, which can be seen in up to $50 \%$ of adult patients with Fragile $X$ syndrome. There are also incidences of mild dilation of aortic root in adults. ${ }^{[24]}$

(h) Chromosome Deletion and duplication Syndromes: Congenital heart lesions are common in most of the macro deletion syndromes and the cardiac anomalies vary widely even in those with apparently identical deletion breakpoints. It includes 3q, 4q, 5p, $8 p, 9 p, 11 q, 13 q, 18 p$, and $18 q$ deletion syndromes. ${ }^{[24]}$ There are an equal number of duplication syndromes that also can be present with multiple congenital malformation and cardiac lesions such as $1 p, 2 p, 2 q, 2 p$, $5 p, 8 p, 13 q$ and $16 q$ duplication syndromes. ${ }^{[24]}$ Many affected children have a combination of deletions and duplications involving the respective chromosome segments that were involved in the rearrangement. Some of them are:

(i) Deletion 22Q11.2 syndrome: It comprises of 3 major syndromes: DiGeorge Syndrome (DGS), Velo cardio Facial syndrome (VCFS) and Conotruncal anomaly face syndrome (CTAFS). Clinically these syndromes have overlapping phenotypes. The land marking features of Digeorge syndromes are heart abnormalities, trouble with calcium level, immune system problems due to the small size or absence of the thymus and or parathyroid. The important features of velocardiofacial syndrome are cleft palate, heart disease, learning disabilities and a characteristic facial appearance. CATCH 22 is the medical acronym of $22 q 11$ deletion syndrome (which stands for Cardiac defect, Abnormal face, Thymic hypoplasia, Cleft palate and Hypocalcemia 22q11.2 deletion). Individuals with this syndrome have a range of findings, including CHDs particularly conotruncal malformations (TOF, IAA, and TA); palatal abnormalities (velopharyngeal incompetence), sub mucosal cleft palate as well as cleft palate; and learning difficulties. The incidence of this syndrome is 1 in 4500 live births. It is sporadic in $\sim 90 \%$ of the cases. This deletion is $\sim 3 \mathrm{Mb}$ long in $90 \%$ of the patients and $1.5 \mathrm{Mb}$ in $10 \%$ of cases. It is estimated to encompass $\sim 30$ genes. It has also been reported that UFD1L gene is not the only target in chromosome $22 q 11$ syndromes for CHDs. ${ }^{[25]}$ Since the recent mouse studies of TBX1 haploinsufficiency have established TBX1 contribution to conotruncal development, it has been hypothesized that human TBX1 haploinsufficiency via chromosome 22q11 deletion plays a major role in human DGS/ VCFS conotruncal disease. ${ }^{[26]}$ Less than $1 \%$ of patients with clinical findings of the 22q11.2 deletion syndrome have a translocation between chromosome 22 and 11..27-28] Standard karyotypic analysis, even with high-resolution banding techniques will only detect $10-20 \%$ of $22 q 11$ deletions. Currently, FISH is the method of choice for microdeletion detection. ${ }^{[29]}$

(ii) Wolf-hirschhorn syndrome: This syndrome is due to deletion of terminal segment of chromosome $4 p{ }^{[30]}$ There is increased incidence of cleft lip, palate, seizures and heart disease (30\%). ${ }^{[31]}$

(iii) 1q21 Microdeletions: Microdeletion on chromosome 1q21.1 spanning between 1.5 to $3 \mathrm{Mb}$ has been reported to be associated with CHDs, particularly anomalies of aortic arch. ${ }^{[32]}$

\section{Other Major "Cardiac" Syndromes}

(a) Noonan syndrome: Children with this syndrome have specific features such as valvar pulmonary stenosis, short stature, mild learning difficulties, and dysmorphic appearance. The cardiac disease seen in this syndrome includes PS, ${ }^{[33]}$ ASD, PDA, VSD and asymmetric septal hypertrophy. ${ }^{[34]}$

(b) Kabuki syndrome: It is characterized by distinct facial anomalies, variable degrees of mental retardation, CHDs and skeletal malformation. The CHDs include ASD, VSD, TOF, PDA, TGA, aortic Coarctation, single ventricle with common atrium and right bundle branch block. ${ }^{[35]}$

(c) Ellis- van Creveld: It shows skeletal dysphasia characterized by short limbs, short ribs, postaxial polydactyly, dysplastic nails and teeth. ${ }^{[36]} \mathrm{CHDs}$ occur in $60 \%$ of affected individuals that are disease in primary atrial septation; single atrium and Hypoplastic left heart syndrome. ${ }^{[37]}$ 


\section{Gene mutations}

At present, very few candidate genes have been identified which cause CHDs in human beings, partly because of lack of large pedigrees segregating a well defined type of CHDs. Some of them are presented in Table 3.

(1) CSX/ NKX2.5: The earliest molecule marker of the cardiac lineage is NKX2.5 in vertebrates. It is one of the members of NK2 family of homeobox genes and a homolog of the Drosophila tinman. It has highly conserved regions of DNA binding, protein-protein interactions, nuclear translocation, and regulation of other transcription factors. Their homeodomains have a tyrosine at position 54, making it the most unambiguous feature of this class and is a useful classification tool. Homeobox genes have been found to play a crucial role in regulating tissue specific gene expression. Mutations in this gene have been reported [Table 4] to cause ASD, VSD with atrial ventricular block, TOF and Tricuspid valve abnormalities. ${ }^{[38-40]}$

(2) GATA4: The heart disease critical region is a $10 \mathrm{cM}$ segment defined by markers distally, D8S1706 and proximally, D8S1759. This region harbors GATA4, a transcription factor which is a member of the GATA family that is zinc finger proteins. The proteins in the GATA family recognize a specific consensus sequence (A/ TGATAA/G) and is known as the "GATA" motif. The mutation in GATA4 gene [Table 4] diminishes DNA-bind-

Table 3: Genes causing different types of CHDs with there chromosomal region in humans ${ }^{[38-52]}$

\begin{tabular}{lll}
\hline Gene & $\begin{array}{l}\text { Chromosome } \\
\text { locus }\end{array}$ & Type of defects \\
\hline CSX/ NKX2.5 & $5 q 34$ & $\begin{array}{l}\text { ASD, VSD, AV block, TOF, } \\
\text { Ebstein malformations and } \\
\text { Tricuspid valve abnormalities } \\
\text { ASD, VSD, AVSD, Pulmonary } \\
\text { valve thickenings }\end{array}$ \\
TBX5 & $8 p 22-23$ & ASD, VSD, AVSD,TOF, \\
dHAND/eHAND & $4 q 33$ and $5 q 33$ & AS \\
IRX4 & $12 q 24.1$ & respectively \\
JAGGED-1 & $5 p 15.3$ & SV \\
Elastin & $20 \mathrm{p} 12$ & TOF \\
TFAP2B & $7 q 11$ & AS \\
Fibrillin & $6 p 12$ & PDA \\
\hline
\end{tabular}

ing affinity and transcriptional activity. GATA4 is capable of synergizing with other transcription factors such as NKX2.5, dHAND and TBX5 to activate cardiac-specific gene expression. ${ }^{[41-42]}$

(3) TBX5: TBX5 is a T-box containing transcription factor expressed early in heart development. ${ }^{[1]}$ In humans missense mutations, which disrupt the 5' end of the T-Box, have more severe cardiac effects than missense mutations at 3 ' end of the T-Box. ${ }^{[42-43]}$ Holt-Oram syndrome is a developmental disorder affecting the heart and upper limbs caused by mutation in the TBX5. The range of cardiac abnormalities include atrioventricular blocks, failure of septa formation, HLHS, AS, mitral valve prolapse, TOF, secundum ASD, VSD, AVSD, and TA. ${ }^{[4]}$

(4) dHAND/eHAND: Human dHAND and eHAND are two related basic helix-loop-helix transcription factors that are expressed in a complementary fashion in the developing right and left ventricles, respectively. They are also expressed in the neural crest-derived cardiac outflow tract and aortic arch arteries. $d H A N D$ mutations exhibit hypoplasia of the right ventricle, branchial arches, and aortic arch arteries. ${ }^{[45]}$ dHAND expression was observed in all four chambers of the healthy human heart. In contrast eHAND was expressed in the right and left ventricles but down regulated in both atrial chambers. ${ }^{[46]}$

(5) IRX4 (Iroquois homeobox gene 4): Human IRX4 which is present in the developing central nervous system, skin, and vibrissae, but are predominantly expressed in the cardiac ventricles. This Homeobox gene is likely to be an important mediator of ventricular differentiation during cardiac development, which is downstream of $N K X 2.5$ and $d H A N D{ }^{[47]}$

(6) JAGGED-1: It is a Notch Ligand, expressed in the developing right heart. Missense mutation (G274D) in JAGGED-1, causes defect in all forms of TOF. Mutation in JAGGED-1 has also been identified in patients with Alagille syndrome. ${ }^{[48]}$

(7) Elastin: A mutation of Elastin causes supravalvular aortic stenosis and peripheral pulmonary artery stenosis. This mutation is also associated with William syndrome. ${ }^{[49]}$

(8) TFAP2B: It is expressed in the neural crest. This mutation was observed in families with PDA, hand anomalies and facial dysmorphism. ${ }^{[50]}$ 
Table 4: Point mutations reported in most probable candidate genes GATA4 and NKX2.5 which causes CHDs in humans

\begin{tabular}{|c|c|c|c|c|}
\hline Gene & Region and gene length & Mutations & Cardiac disease & References \\
\hline$N K X 2-5$ & $\begin{array}{l}5 q 34, \\
1585 \text { bp, } \\
324 \text { residues }\end{array}$ & $\begin{array}{l}\text { Int 1DSG+1T } \\
\text { C554T(Gln149ter) } \\
\text { C618T(Gln170ter) } \\
\text { C642T(Thr178Met) } \\
\text { C673A(Asn188Cys) } \\
\text { C674G(Arg189Gly) } \\
\text { A681G(Tyr191Cys) } \\
\text { C701T(Gln198ter) } \\
\text { C886A(Tyr259ter) } \\
\text { C182T(Arg25Cys) } \\
\text { A44T(Lys15lle) } \\
\text { G61(Glu21Gln) } \\
\text { A65C(Gln22Pro) } \\
\text { C73T(Arg25Cys) } \\
\text { C188T(Ala63Val) } \\
\text { C380A(Ala127Glu) } \\
\text { C646T(Arg216Cys) } \\
\text { C656T(Ala219Val) } \\
\text { Ins TCCCT701(D235AFSter) } \\
\text { C823A(Pro275Thr) } \\
\text { del AAC871(del291Asn) } \\
\text { G967A(Ala323Thr) }\end{array}$ & $\begin{array}{l}\text { TOF, VSD, ASD, AV block, } \\
\text { valve abnormalities, Double- } \\
\text { outlet right Ventricle } \\
\text { abnormalities, Ebstein } \\
\text { malformations }\end{array}$ & $\begin{array}{l}\text { Schott et al }{ }^{\left[{ }^{[38]}\right.} \text { Hosoda et al[72] } \\
\text { and Benson et al, }{ }^{[39]}\end{array}$ \\
\hline GATA4 & $\begin{array}{l}8 \mathrm{p} 22-23,3375 \mathrm{bp}, \\
443 \text { residues }\end{array}$ & $\begin{array}{l}\text { G296S(missense mutation) } \\
\text { E359del(frame shift mutation) }\end{array}$ & $\begin{array}{l}\text { ASD,VSD, AVSD, } \\
\text { Pulmonary valve thickenings }\end{array}$ & Garg et al, ${ }^{[41]}$ \\
\hline
\end{tabular}

(9) Fibrillin: Mutation in this gene causes cardiac disease that include dilation of ascending aorta, mitral valve prolapse and dilation of pulmonary artery. ${ }^{[51-52]}$

\section{Conclusion and Future prospects}

Heart development, is early in the embryo leading to significant mortality and morbidity affecting the clinical outcome of the affected individuals. This review firstly provides an understanding of different types of heart lesions clinically. Secondly it provides information which shows a significant incidence of heart defects and chromosomal abnormalities having extra cardiac anomalies and thirdly the similar mutations which are the devastating events of molecular mechanism may be the cause of different types of CHDs indicating the involvement of single gene defects.

In order to explain the causes of CHDs we have created a simple integrated model [Figure 2]. The major components involved in CHDs are environmental factors, mutations in chromosomes and genes. This model will help us to delineate the complex CHDs, wherein it explains how a single gene is responsible for various types of CHDs phenotypes as well as how a single $\mathrm{CHD}$ is caused by the involvement of different genes. If one look into the functions of these genes and their products one can clearly follow the pathways how CHDs are formed.

Finally, the completion of the human genome project has provided a range and depth of information never before imagined. It has brought lot of importance and challenge to understand the genetic disease. Further challenges include utilizing this emerging genetic information to improve diagnosis and treatment of children with CHDs, and harnessing the power of genomics to analyze isolated heart disease with complex inheritance patterns. We need to extend the ability of physicians to find heart defects as early as possible so that, they can be treated while the heart is still forming. It is expected that once we identify specific genetic basis for cardiac defects it should be possible to identify and treat individuals who might be at risk at an early stage. 
Genetic Material

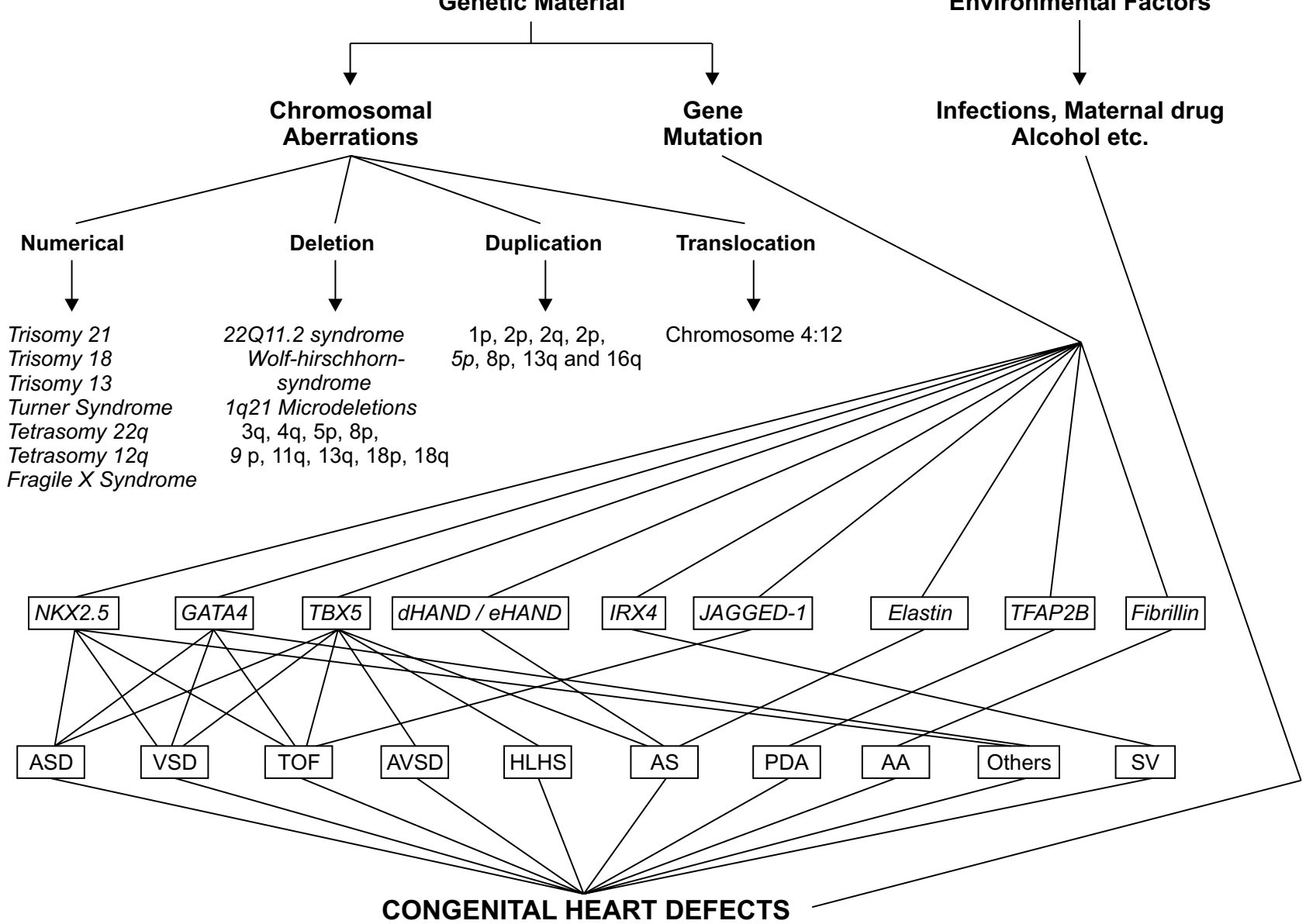

Figure 2: Model to understand the etiology of CHDs. The environmental factors, mutations in chromosomes and genes are the causative agents of CHDs. This model explains how a single gene is responsible for various types of CHD phenotypes and how a single CHD is caused by the involvement of different genes as well as how different genes interact to produce CHDs

As we enter the post genomic era, the enormous information about the types of CHDs, its association and the causes, available will enable us to understand one of the most complex disorders that are CHDs.

\section{Acknowledgments}

We are thankful to Head and members of Paediatric Department in different hospitals at Mysore; Prof. H. A. Ranganath, and Chairman of Department of Zoology, University of Mysore; Mr. Harshvardhan. M. Gawde and Dr. Mikhil. N. Bamne, Mumbai for their cooperation, help and encouragement.

\section{References}

1. Srivastava D. Genetic assembly of the heart: Implication of congenital heart disease. Annu Rev Physiol 2001;63:451-69.

2. Epstein JA, Buck CA. Transcriptional Regulation of cardiac development implications for CHD and Digeorge syndrome. Pediatr Res 2000;48:717-24.
3. Bruneau BG. Transcriptional regulation of vertebrate cardiac morphogenesis. Circ Res 2002;90:509-19.

4. http://www.americanheartassociation.com/Heart disease and stroke statistics-2003 update

5. Frias JL. Genetic issues of congenital heart disease. In: Gessner IH, Victrorica BE, editors. Pediatric cardiology. Philadelphia: Saunders; 1993. p. 237-42.

6. Hoffman JI, Kaplan S. The incidence of congenital heart disease. J Am Coll Cardiol 2002;39:1890-900.

7. Chadha SL, Singh N, Shukla DK. Epidemiological study of congenital heart disease. Indian $\mathrm{J}$ Pediatr 2001;68:507-10.

8. Thakur JS, Negi PC, Ahluwalia SK, Sharma R, Bhardwaj R. Congenital heart disease among school children in Shimla hills. Indian Heart J 1995;47:232-5.

9. Pizarro A, Diaz R. Analysis of congenital heart anomalies 1990-1997. Presented at INABIS' $98-5^{\text {th }}$ internet world congress on biomedical sciences at McMaster University, Canada, Dec 7-16 ${ }^{\text {th }}$.

10. http://www.americanheartassociation.com/The Merck Manual of Diagnosis.

11. Zaret BL. Diagnosis: Steps In Making A Diagnosis, Chapter 10. p. 115-28.

12. Payne M, Johnson MC, Grant JW, Strauss AW. Towards a molecular understanding of congenital heart disease. 
Circulation 1995;91:494-504.

13. http://www.noah.cuny.edu/pregnancy/march_of_dimes/ birth_disease/congnitl.html

14. Burn J, Goodship J. Development genetics of the heart. Curr Opin Genet Dev 1996;6:322-5.

15. Chaoui R, Korner H, Bommer C, Goldner B, Bierlich A, Bollmann R. Prenatal diagnosis of heart disease and associated chromosomal aberrations. Ultraschall Med 1999;20:177-84.

16. Hook EB, Fabia JJ. Frequency of Down syndrome in live births by single year maternal age interval; results of a Massachusetts study. Teratology 1978;17:223-8.

17. Root S, Carey JC. Survival in trisomy 18. Am J Med Genet 1994;49:170-4.

18. Musewe NN, Alexander DJ, Teshima I, Smallhorn JF, Freedom RM. Echocardiographic evaluation of the spectrum of cardiac anomalies associated with trisomy 13 and trisomy 18. J Am Coll Cardiol 1990;15:673-7.

19. Chu CE, Donaldson MD, Kelnar CJ, Smail PJ, Greene SA, Paterson WF, et al. Possible role of imprinting in the Turner phenotype. J Med Genet 1994;31:840-2.

20. Mazzanti L, Cacciari E. Congenital heart disease in patients with Turners syndrome. Italian study group for Turner syndrome (ISGTS). J Pediatr 1998;133:688-92.

21. Paul T, Reimer A, Wilken M, Miller K, Kallfelz HC. Complex cyanotic heart disease in a new born infant with cat eye syndrome. Monatsschr Kinderheilkd 1991;139:228-30.

22. Reylonds JF, Daniel A, Kelly TE, Gollin SM, Stephan MJ, Carey J, et al. Isochromosome 12pmosaicism (Pallister mosaic aneuploidy or Pallister-Killian syndrome): Report of 11 cases. Am J Med Genet 1987;27:257-74.

23. Hagerman R. Fragile $X$ syndrome In: Cassidy SB, Allanson JE, editors. Management of Genetic Syndrome. New York: Wiley-Liss; 2001;554:165-83.

24. Prasad C, Chudley AE. Genetics and Cardiac Anomalies: the Heart of the Matter. Indian J Pediatr 2002;69:321-32.

25. Chung MY, Lu JH, Weng YY, Hwang B. Absences of mutations in human Ubiquituin fusion-degradation protein gene in Teratology of Fallot. J Mol Med 2001;79:338-42.

26. Kim MS, Basson CT. Wrapping up DiGeorge Syndrome in a T-box?. Nature Genet 2001;27:286-91.

27. Driscoll DA, Budarf MI, Emanuel BS. A genetic etiology of Digeorge syndrome. Genomics 1991;10:201-6.

28. Wilson DI, Cross IE, Goodship JA, Brown J, Scambler $\mathrm{PJ}$, Bain $\mathrm{HH}$, et al. A prospective Cytogenetic study of 36 cases of Digeorge syndrome. Am J Hum Genet 1992;51:957-63.

29. Goldmutz E, Geiger E, Benson W. NKX2.5 mutations in patients with TOF. Circulation 2001;104:2565-8.

30. Johnson VP, Mulder RD, Hosen R. The Wolf-Hirschhorn (4p) syndrome. Clin Genet 1976;10:104-12.

31. Battaglia A, Carey JC, Cederholm P, Viskochil DH, Brothman AR, Galasso C. Natural history of WolfHirschhorn syndrome: Experience with 1 case. Pediatrics 1999;103:830-6.

32. Christiansen J, Dyck JD, Elyas BG, Lilley M, Bamforth JS, Hicks M, et al. Chromosome 1q21.1 Contiguous Gene Deletion is Associated with Congenital heart disease. Circ Res 2004. p. 1-7.

33. Burch M, Sharland M, Shinebourne E, Smith G, Patton M, McKenna W. Cardiologic abnormalities in Noonan syndrome phenotypic diagnosis and echocardiographic as- sessment of 118 patients. J Am Coll Cardiol 1993;22:1189-92.

34. Marino B, Digilio MC, Novelli G, Giannotti A, Dallapiccola B. Tricuspid Artesia and 22 q11 deletion. Am J Med Genet 1997;72:40-2.

35. Digilio MC, Marino B, Toscano A, Giannotti A, Dallapiccola B. Congenital heart disease in Kabuki syndrome. Am J Med Genet 2001;100:269-74.

36. Mc Kusick VA. Ellis-Van Creveld syndrome and the Amish. Nat Genet 2000;24:203-4.

37. Ruiz-Perez VL, Ide SE, Strom TM, Lorenz B, Wilson D, Woods $\mathrm{K}$, et al. Mutations in a new gene in Ellis-Van creveld syndrome and weyers acrodental dysostosis. Nat Genet 2000;21:283-6.

38. Schott JJ, Benson DW, Basson CT, Pease W, Silberbach MG, Moak JP, et al. Congenital heart disease caused by mutations in the transcription factor NKX2.5. Science 1998;281:108-11.

39. Benson DW, Silberbach GM, Kavanaugh-McHugh A, Cottrill C, Zhang Y, Riggs S, et al. Mutations in the cardiac transcription factor NKX2.5 affect diverse cardiac development pathways. J Clin Invest 1999;104:1567-73.

40. McElhinney DB, Geiger E, Blinder J, Benson W, Goldman E. NKX2.5 Mutations in patients with congenital heart disease. American J Cardiol 2003;42:1650-5.

41. Garg V, Kathiriya IS, Barnes R, Schluterman MK, King IN, Butler CA, et al. GATA4 mutations cause human congenital heart disease and reveal an interaction with TBX5. Nature 2003;424:443-7.

42. Basson CT, Bachinsky DR, Lin RC, Levi T, Elkins JA, Soults $\mathrm{J}$, et al. Mutation in human TBX5 cause limb and cardiac malformation in Holt Oram syndrome. Nat Gent 1997;15:30-5.

43. Yang J, Hu D, Xia J, Yang Y, Ying B, Hu J, et al. Three novel TBX5 mutations in Chinese patients with Holt Oram syndrome. Am J Med Genet 2000;92:237-40.

44. Li QY, Newbury-Ecob RA, Terrett JA, Wilson DI, Curtis $\mathrm{AR}, \mathrm{Yi} \mathrm{CH}$, et al. Holt Oram syndrome is caused by mutations in TBX5 a member of the Brachyury (T) gene family. Nat Genet 1997;15:21-9.

45. Srivastava D. HAND proteins: Molecular mediators of cardiac development and congenital heart disease. Trends Cardiovasc Med 1999;9:11-8.

46. Natarajan A, Yamagishi H, Ahmad F, Li D, Roberts R, Matsuoka R, et al. Human eHAND, but not dHAND is down regulated in cardiomyopathesies. $\mathrm{J}$ Mol Cell Cardiol 2001;33:1607-14.

47. Bruneau BG, Bao ZZ, Tanaka M, Schott JJ, Izumo S, Cepko CL, et al. Cardiac expression of the ventricle-specific homeobox gene Irx4 is modulated by Nkx2-5 and dHand. Dev Biol 2000;217:266-77.

48. Li L, Krantz ID, Deng Y, Genin A, Banta AB, Collins CC, et al. Alagille syndrome is caused by Mutations in human Jagged 1, which encodes a Ligand for Notch 1. Nat Genet 1997;16:243-51.

49. Zalzstein E, Moes CA, Musewe NN, Freedom RM. Spectrum of cardiovascular anomalies in Williams Beuren syndrome. Pediatr cardiol 1991;12:219-23.

50. Sacoda M, et al. Mutations in TFAP2B cause char syndrome a familial form of patent ductus arteriosus. Nature Genet 2000;25:42-6.

51. Francke U, Furthmayr H. Genes and gene products involved in Marfan syndrome. Semin Thorac Cardiovasc Surg 1993;5:3-10. 
52. Srivastava D, Olson EN. A genetic blue print for cardiac development. Nature 2000;407:221-6.

53. Bound JP, Logan WF. Incidence of congenital heat disease in Blackpool 1957-1971. Br Heart J 1977;39:445-50.

54. Kenna AP, Smithells RW, Fielding DW. Congenital heart disease in Liver pool: 1960-69. Q J Med 1975;44:17-44.

55. Samanek M, Slavik Z, Krejcir M. Seasonal differences in the incidence of congenital heart disease. Czech Med 1991;14:146-55.

56. Bitar FF, Baltaji N, Dbaibo G, Abed el-Jawad M, Yunis $\mathrm{KA}$, Obeid M. Congenital heart disease at a tertiary care centre in Lebanon. J Anesthesiol 1999;15:151-64.

57. Samanek M, Slavik Z, Krejcir M. Congenital heart disease among 815,569 children born 1980 and 1990 and their 15 year survival: A prospective Bohemia survival study. Pediatr Cardiol 1999;20:411-7.

58. Bower C, Ramsay JM. Congenital heart disease: A 10 year cohort. J Paediatr Child Health 1994;30:414-8.

59. Kidd SA, Lancaster PAL, McCredie RM. The incidence of congenital heart disease in the first year of life. J Paediatr Child Health 1993;29:344-9.

60. Robida A, Folger GM, Hajar HA. Incidences of congenital heart disease in Qatari children. Int $\mathrm{J}$ Cardiol 1997;60:19-22.

61. Meberg A, Otterstad JE, Froland G, Sorland S, NitterHauge $S$. Increasing incidence of ventricular septal disease caused by improved detection rate. Acta Paediatr 1994;83:653-7.

62. Hassan I, Haleem AA, Bhutta ZA. Profile and risk factors for congenital heart disease. J Pak Med Assoc 1997;47:78-81.

63. Bolisetty S, Daftary A, Ewald D, Knight B, Wheaton G.
Congenital heart disease in Central Australia. Med J Aust 2004;180:614-7.

64. 1998 Annual report of the South Australian Birth Disease Register. Adelaide: Women's and Children's Hospital; 2000. p. 7.

65. Subramanyan R, Joy J, Venugopalan P, Sapru A, al Khusaiby SM. Incidence and spectrum of congenital heart disease in Oman. Ann Trop Paediatr 2000;20:337-41.

66. Begic $H$, Tahirovic $H$, Mesihovic-Dinarevic S, Ferkovic $\mathrm{V}$, Atic $\mathrm{n}$, Latifagic A. Epidemiological and clinical aspects of congenital heart disease in children in Tuzla Canton, Bosnia-Herzegovina. Eur J Pediatr 2003;162:191-3.

67. Bassili A, Mokhtar SA, Dabous NI, Zaher SR, Mokhtar MM, Zaki A. Congenital heart disease among school children in Alexandria, Egypt: An overview on prevalence and relative frequencies. J Trop Pediatr 2000;46:357-62.

68. Alabdulgader A. Congenital heart disease in 740 subjects: Epidemiological aspects. Ann Trop Paediatr 2001;21:111-8.

69. Venugopalan P, Agarwal AK. Spectrum of congenital heart disease associated with Downs in high consanguineous Omani population. Int J Cardiol 2002;4:211-6.

70. Wickramasinghe $P$, Lambadusuriya SP, Narenthiran S. Prospective study of congenital heart disease in children. Ceylon Med J 2001;46:96-8.

71. Suresh V, Rao AS, Yavagal ST. Frequency of various congenital heart disease: analysis of 3790 consecutively catheterized patients. Indian heart J 1995;7:125-8.

72. Hosoda T, Komuro I, Shiojima I, Hiroi Y, Harada M, Murakawa $Y$, et al. Familial atrial septal disease and atrioventricular conduction disturbance associated with a point mutations in the cardiac homeobox gene CSX/NKX2.5 in a Japanese patient. Jpn Circ J 1999;63:425-6. 